\title{
COVID-19 and olfactory dysfunction - an ENT perspective to the current COVID-19 pandemic
}

\author{
Anneclaire V. Vroegop ${ }^{1,2}$ (D), Anne-Sophie Eeckels ${ }^{1,2}$ (D), Vincent Van Rompaey ${ }^{1,2}$ (D), Dirk Vanden Abeele ${ }^{3}$ (D), Michele Schiappoli ${ }^{4}$ (D), \\ Isam Alobid ${ }^{5}$ (D) Thomas Hummel $^{6}$ (D) Clotilde De Dorlodot $^{7}$ (D), Patrick Levie ${ }^{1,8}$ (D), Caroline Huart ${ }^{9}$ (D) Philippe Eloy ${ }^{7}$ (D), \\ Olivier M. Vanderveken ${ }^{1,2}$ (D), Peter W. Hellings ${ }^{10}$ (D) Philippe Rombaux $^{8}$ (D), Philippe Gevaert ${ }^{11}$ (D)

\begin{abstract}
1'Department of Otorhinolaryngology, Head and Neck Surgery, Antwerp University Hospital, Edegem, Antwerp, Belgium
${ }^{2}$ Translational Neurosciences, Faculty of Medicine and Health Sciences, University of Antwerp, Antwerp, Belgium

${ }^{3}$ Department of Otorhinolaryngology, Head and Neck Surgery, GZA Hospital Sint-Vincentius, Antwerp, Belgium

${ }^{4}$ Asthma Center and Allergy Unit, Verona University Hospital, Verona, Italy

${ }^{5}$ Rhinology Unit \& Smell Clinic, ENT Department, Hospital Clinic Barcelona, Barcelona, Spain

${ }^{6}$ Department of Otorhinolaryngology, Smell \& Taste Clinic, TU Dresden, Dresden, Germany

${ }^{7}$ Department of Otorhinolaryngology, Head and Neck Surgery, CHU UCL Namur, Yvoir, Belgium

${ }^{8}$ Department of Otorhinolaryngology, Head and Neck Surgery, CHIREC / Clinic Messidor, Brussels, Belgium

${ }^{9}$ Department of Otorhinolaryngology, Institute of Neuroscience, Université Catholique de Louvain, Brussels, Belgium, Cliniques Universitaires

Saint-Luc, Brussels, Belgium

${ }^{10}$ Department of Otorhinolaryngology, Head and Neck Surgery, University Hospitals Leuven, KU Leuven, Belgium

${ }^{11}$ Department of Otorhinolaryngology, Ghent University, Ghent University Hospital, Ghent, Belgium
\end{abstract}

Cite this article as: Vroegop AV, Eeckels AS, Van Rompaey V, et al. COVID-19 and olfactory dysfunction - an ENT perspective to the current COVID-19 pandemic. B-ENT 2020; 16(1): 81-5.

\begin{abstract}
The current COVID-19 or Sars-CoV-2 pandemic increased awareness of hyposmia or anosmia, as this can be an accompanying symptom. In mild cases, anosmia without rhinorrhea can be the only presenting symptom of this infection. Timely identification can lead to early detection of otherwise asymptomatic carriers. History taking and essential clinical assessment with appropriate protective measures can be performed in patients in whom COVID-19 is suspected. Patients with anosmia without nasal obstruction should be considered COVID-19 suspect and this should initiate testing or self-isolation. As for treatment of hyposmia or anosmia, the authors do not advise treatment with systemic corticosteroids in patients with COVID-19. Based on expert opinion, nasal corticosteroids can be considered, with a preference for spray formulation. Patients who were already using topical or inhalation corticosteroids for proven pre-existing disease (such as asthma and/or allergy) should be advised to continue their maintenance therapy. ENT (Ear Nose Throat) focus on hyposmia and anosmia should be continued, to gain additional knowledge of the disease mechanisms of COVID-19 and improve follow-up, not only on the pneumological aspects but also to evaluate the impact on quality of life of potentially long-term side effects caused by anosmia.
\end{abstract}

Keywords: Anosmia, COVID-19, hyposmia, olfactory dysfunction, respiratory tract infection

\section{Introduction on olfactory (dys)function}

Olfactory function is part of the chemosensory system and important for digestive behavior as it helps to detect and enjoy food. In addition, it is of importance for social communication and the detection of environmental hazards (1). Processing of olfactory information includes smell receptor stimulation in the olfactory mucosa, adequate neural transmission by the olfactory nerves and processing by the olfactory bulb, parts of the limbic system and the neocortex (2).
Olfactory disorders such as anosmia and hyposmia are estimated to affect $3-20 \%$ of the population (1). Apart from aging, three major causative disorders have been identified. Typically, in tertial referral centers these causes include nasal and paranasal sinus disease $(21 \%)$, infections of the upper respiratory tract $(19 \%)$, and head trauma (14\%). In $22 \%$ of patients no identifiable cause is found $(3,4)$. Other potential causes include neurodegenerative diseases, structural brain disease, toxic chemical exposure, metabolic diseases and side effects of medication or drugs $(2,5)$. Improvement

Corresponding Author: Anneclaire V. Vroegop; avmtvroegop@gmail.com

Received: April 19, 2020 Accepted: April 22, 2020 Available Online Date: May 2, 2020

Available online at www.b-ent.be

CC BY 4.0: Copyright@Author(s), “Content of this journal is licensed under a Creative Commons Attribution 4.0 International License." 
in olfactory function is inversely correlated with the severity and duration of loss of smell, age, smoking, and male sex; up to one-half of patients with olfactory dysfunction improves over time, although for post-traumatic loss improvement is noted only around $10-20 \%$ (5). As for (post-)infectious olfactory disorders, the pathophysiology remains poorly delineated, but is thought to involve either damage to the olfactory neuroepithelium (peripheral) or central olfactory processing pathways and can persist in $6-13 \%$ of cases $(6-11)$. It was demonstrated that $80 \%$ of the patients with post-viral olfactory loss reported subjective recovery after one year, but only $32 \%$ reported normosmia; the more favorable prognosis was associated with longer follow-up duration and female gender (12). The varying rates and degree of post-infectious olfactory dysfunction can be explained by the differences in affecting the central olfactory pathways $(2,6)$.

Depending on the specific cause, standard treatment of olfactory disorders in the course of chronic rhinosinusitis usually includes intranasal corticosteroid and oral corticosteroid treatment. The routine work-up of patients with taste or smell disorders includes a thorough structured history, ENT examination as well as neurologic examination (focusing on cranial nerves I, VII, IX, and X) and additional assessment including computed tomography (CT) and/or brain magnetic resonance imaging (MRI) $(5,13)$. A well-specified history is also important to distinguish between smell and taste disorders, as complaints of taste loss usually reflect loss of smell function (14). Numerous techniques are available in the clinic for the investigation of chemosensory function and psychophysical testing using orthonasal and retronasal stimulation routes helps to distinguish anosmic from hyposmic patients (15). These psychophysical tests are needed to objectively verify the patient's complaints which can often be misleading $(16,17)$. Olfactory training appears to be a promising therapy for patients with post-viral olfactory loss to partly regain their sense of smell (18).

\section{COVID-19 and olfactory dysfunction}

Currently, the World Health Organization (WHO) has announced a pandemic infection with a previously unknown

\section{Main Points:}

Patients with anosmia without nasal obstruction should be considered COVID-19 suspect and this should initiate testing or self-isolation.

Based on currently available literature, the authors do not advise treatment with systemic corticosteroids.

Although there is no evidence-based indication for intranasal corticosteroid, based on expert opinion, the use of intranasal corticosteroids can be considered, with a preference for spray formulation.

Patients who were already using topical or inhalation corticosteroids for proven pre-existing disease (such as asthma and/or allergy) should be advised to continue their maintenance therapy.

Follow-up of olfactory function is indicated and olfactory training can be started in cases where olfactory dysfunction persists. species of coronavirus, called COVID-19 or SARS-CoV-2. This infection is transmitted mainly through droplets and aerosols, and, causes mild symptoms in the majority of cases. The most common symptoms are fever, dry cough, fatigue, anorexia and myalgia; less common symptoms include headache, sore throat, rhinorrhea, and gastrointestinal symptoms (e.g., nausea and diarrhea) (19). Life-threatening complications of COVID-19 are acute respiratory distress syndrome (ARDS), arrythmia, myocardial injury and shock (20).

Recent studies report anosmia and dysgeusia as two of the first symptoms of COVID-19 $(21,22)$. Dysgeusia could be the result of an altered perception of taste caused by the loss of sense of smell, and it might actually point towards a confusion of taste and retronasal olfactory function, i.e. flavor $(23,24)$. Olfactory dysfunction has been reported as the only symptom in patients with very mild disease. The COVID-19 pandemic has thus led to increased awareness of hyposmia and anosmia, as reports from epicenters show that smell and taste disorders can be first signs of this infection (25-27). There is anecdotal information about the prevalence, onset, and evolution of anosmia, hyposmia and dysgeusia in COVID-19 patients. The first data on anosmia in patients are published by clinicians in the field and spread by special reports of medical associations $(21,28)$.

In a survey of 59 COVID-19 patients by Giacomelli et al. (29), twenty patients (33.9\%) reported at least one taste or olfactory disorder(s) and eleven participants (18.6\%) reported both. These authors state that olfactory dysfunction is frequently related to COVID-19 infection and may precede the onset of the disease. The authors refer to the underlying mechanisms as described in mouse models by Netland et al. (30), that demonstrate that SARS-CoV enters the brain primarily via the olfactory bulb, and infection results in rapid, transneuronal spread to connected areas of the brain. Brann et al. (31) reported that ACE-2 receptor, the main host cell receptor of 2019-nCoV playing a crucial role in the entry of virus into the cell to cause the final infection, is expressed on the mucosa of oral cavity and highly enriched in epithelial cells of the tongue. Particularly at the level of the olfactory epithelium, ACE-2 and TMPRSS2 genes are expressed by olfactory sustentacular cells and olfactory stem cells.

Eliezer et al. (32) reported a case where the main symptom expressed by the patient infected by SARS-CoV-2 was the sudden and complete loss of the olfactory function without nasal obstruction. They report that cases of sudden and complete olfactory function loss without nasal obstruction in a patient with other symptoms, such as cough or fever, should alert the clinician to suspect SARS-CoV-2 infection. Vaira et al. (21) report olfactory dysfunction based on history and physical examination in $19.4 \%$ out of 320 patients. Kaye et al. reported the initial findings of the anosmia reporting tool on COVID-19 cases for clinicians worldwide (23). Out of 237 entries they noted anosmia prior to COVID-19 diagnosis in $73 \%$ while anosmia was the initial symptom in $26.6 \%$ of the patients. A recent European multicenter study by Lechien et al. (33) investigated self-reported olfactory dysfunction in 417 mild to moderate COVID-19 cases. Olfactory dysfunction was reported in $85.6 \%$ of cases and this occurred in $11.8 \%$ before 
the presence of other symptoms. Out of the $18.2 \%$ of patients without nasal obstruction or rhinorrhea, $79.7 \%$ were hyposmic or anosmic.

However, a study from China reported that the ratio of patients complaining of loss of smell and loss of taste was only $5.1 \%$ and $5.6 \%$ respectively (34). Yan et al. (35) included a total of 1480 patients with influenza-like symptoms that underwent COVID-19 testing. Smell and taste loss were reported in $68 \%$ and $71 \%$ of COVID-19 positive subjects, respectively, compared to $16 \%$ and $17 \%$ of COVID-19 negative patients $(p<0.001)$. Klopfenstein et al. (36) analysed 114 confirmed COVID-19 patients and the results demonstrated anosmia to be present in $47 \%$, associated with dysgeusia in $85 \%$, of cases. Anosmia was never the first or second symptom to develop, but it was the third symptom in $38 \%$ of cases. Anosmia developed 4.4 days after infection onset. The first study using smell quantitative assessment (University of Pennsylvania Smell Identification Test / UPSIT) demonstrated that $98 \%$ of COVID-19 patients $(n=60)$ exhibited at least some smell dysfunction. Thirty-five of the 60 patients $(58 \%)$ were either anosmic (25\%) or severely hyposmic (33\%) (37). The varying rates might be explained by differences in clinical work-up, specific regional patient characteristics or viral strains.

In the current issue of B-ENT (March 2020), the group of $\mathrm{Ca}-$ pelli et al. (38) describes a statistically significant increase in the incidence of hyposmia in the Lombardy city of Codogno, in the epicenter of the COVID-19 outbreak in Italy, in the period between February 21 and March 15, 2020 compared to the incidence of the same symptom in other periods. This and other research will lead to further investigations to determine whether or not hyposmia can be part of the case definition of COVID-19 and what the outcome is after long-term follow-up.

As for the treatment, until now experts and the first reports suggest recovery in the first two weeks after onset of anosmia, but data are still limited. The European Rhinologic Society (ERS) and the ENT UK association advise against giving systemic corticosteroids to patients with sudden olfactory dysfunction since recovery can occur in the first weeks after onset $(39,40)$. Administering topical nasal corticosteroids in patients with anosmia remains controversial. The ERS and French Agency advocate against the use of nasal corticosteroids in patients with olfactory and gustatory dysfunction without nasal obstruction $(40,41)$. Although there is no evidence-based indication for intranasal corticosteroid, based on expert opinion, the use of intranasal corticosteroids can be considered, with a preference for spray formulation over gel or drops due to potential viral spill to the lower respiratory tract with the latter formulations. Also based on expert opinion, if topical corticosteroids are considered they should be administered with a long applicator so the olfactory cleft can be reached $(42,43)$. There can be a role for olfactory training, as it enables improvement of post-infectious olfactory dysfunction in general and it appears to be particularly useful in patients who start it within 12 months after onset (44). A course of topical vitamin A might be considered useful (45). In addition, some experts suggested Zinc as a useful supplement as this is reported to be beneficial to an adequate immune response, can possibly reduce the risk of infection and is investigated for its contribution to olfaction as well $(46,47)$. Some evidence also suggests the potential usefulness of lipoic acid and omega 3 in the management of olfactory disorders $(45,48)$.

According to the ENT associations and recent emerging evidence patients presenting with sudden anosmia without nasal obstruction should be considered as COVID-19 suspect (28, $32,33,40)$. Therefore, targeted COVID-19 testing in these subjects could be helpful in diagnosing new Sars-CoV-2 infections. Hereby, asymptomatic carriers could be identified as soon as possible, and viral transmission could be limited. This could also serve as a new criterion for early self-isolation for $1-2$ weeks $(28,41,49)$.

Recent studies based on a review of treatment of ARDS suggest no benefit from systemic corticosteroids can be expected in COVID-19 cases (50). Because of the immunosuppressive properties mentioned by some, this could lead to prolonged viral replication and worsening of the condition $(50,51)$. The Centers for Disease Control and Prevention (CDC) and the WHO recommend not giving systemic corticosteroids to patients with COVID-19 pneumonia except for specific casebased indications (e.g., chronic obstructive lung disease exacerbation or septic shock) $(19,52,53)$.

According to the ARIA-EEACI (Allergic Rhinitis and its Impact on Asthma \& European Academy of Allergy and Clinical Immunology) statement, it is advised to continue intranasal corticosteroids in patients with allergic rhinitis. Even if they become infected by COVID-19, there is no evidence that this could lead to deterioration or a worse outcome. It is also contraindicated to cease intranasal corticosteroids in patients with a common allergy, especially during the spring season, since this could lead to more sneezing and thus easier transmission of the virus in otherwise asymptomatic carriers (54). Several experts (personal communication) have the impression that patients with type 2 helper T (Th2) cells inflammation such as allergic rhinitis (AR) and chronic rhinosinusitis with nasal polyps (CRSwNP) are less prone to infection by COVID-19, with only speculation as to why this may be the case. Furthermore, nasal corticosteroids have been associated with epithelial barrier restoring effects in $A R$ and in CRSwNP, hence rendering the mucosa of individuals less accessible to external harmful triggers such as viruses (55). In addition, a recent study of Zhang et al. reports that patients with allergic diseases or asthma are not at an increased risk for SARS-CoV-2 infection (56). Therefore, the Global Initiative for Asthma (GINA) advises to continue inhaled corticosteroid controller medication. They also recommend continuing prescribed oral corticosteroids in severe asthma and during severe asthma attacks since this could otherwise lead to dangerous situations (57).

\section{Conclusion}

The current COVID-19 or Sars-CoV-2 pandemic increased awareness of hyposmia or anosmia, as this can be an accompanying symptom. In mild cases, anosmia without rhinorrhea can be the only presenting symptom of this infection. Timely identification can lead to early detection of otherwise asymptomatic carriers. History taking and essential clinical assessment with appropriate protective measures can be performed 
in patients in whom COVID-19 is suspected. Especially in severe COVID-19 cases, key item in the acute setting is without doubt treatment of potentially life-threatening lung disease. As for treatment of hyposmia or anosmia, nasal corticosteroids can be considered. ENT focus on hyposmia and anosmia should be continued, to gain additional knowledge of the disease mechanisms of COVID-19 and improve follow-up, not only on the pneumological aspects but also to evaluate the impact on quality of life of potentially long-term side effects caused by anosmia.

\section{Recommendations}

- Based on currently available literature, the authors do not advise treatment with systemic corticosteroids.

- Although there is no evidence-based indication for intranasal corticosteroid, based on expert opinion, the use of intranasal corticosteroids can be considered, with a preference for spray formulation (preferably with a long applicator) over gel or drops due to potential viral spill to the lower respiratory tract with the latter formulations.

- Patients who were already using topical or inhalation corticosteroids for proven pre-existing disease (such as asthma and/or allergy) should be advised to continue their maintenance therapy.

- Based on expert opinion, intranasal vitamin A application can also be considered.

- Patients with anosmia without nasal obstruction should be considered COVID-19 suspect and this should initiate testing or self-isolation.

- Follow-up of olfactory testing is indicated, and olfactory training can be started in cases where olfactory dysfunction persists.

Peer-review: Externally peer-reviewed.

Author Contributions: Concept - O.M.V.; Design - A.V.V.; Supervision - P.G., O.V., P.H.; Resources - A.V.V., A.S.E., V.V.R., D.V.A., M.S., I.A., T.H., C.D.D., P.L., C.H., P.E., C.M.V., P.W.H., P.R., P.G.; Literature Search - A.V.V., A.S.E.; Writing Manuscript - A.V.V., A.S.E.; Critical Review A.V.V., A.S.E., V.V.R., D.V.A., M.S., I.A., T.H., C.D.D., P.L., C.H., P.E., C.M.V., P.W.H., P.R., P.G.

Conflict of Interest: The authors have no conflicts of interest to declare.

Financial Disclosure: The authors declared that this study has received no financial support.

\section{References}

1. Boesveldt $S$, Postma EM, Boak D, et al. Anosmia-a clinical review. Chem Senses 2017; 42: 513-23. [CrossRef]

2. Mann NM, Lafreniere D. Overview of taste and olfactory disorders in adults. UpToDate 2020. Available at: www.uptodate.com/contents/overview-of-taste-and-olfactory-disorders-in-adults

3. Mott AE, Leopold DA. Disorders in taste and smell. Med Clin North Am. 1991; 75: 1321-53. [CrossRef]

4. Hummel T, Landis BN, Huttenbrink KB. Smell and taste disorders. GMS Curr Top Otorhinolaryngol Head Neck Surg 2011; 10: Doc04. [CrossRef]

5. Malaty J, Malaty IA. Smell and taste disorders in primary care. Am Fam Physician 2013; 88: 852-9.
6. Konstantinidis I, Haehner A, Frasnelli J, et al. Post-infectious olfactory dysfunction exhibits a seasonal pattern. Rhinology 2006; 44: 135-9.

7. Doty RL. A review of olfactory dysfunctions in man. Am J Otolaryngol 1979; 1: 57-79. [CrossRef]

8. Yao L, Yi X, Pinto JM, et al. Olfactory cortex and olfactory bulb volume alterations in patients with post-infectious Olfactory loss. Brain Imaging Behav 2018; 12: 1355-62. [CrossRef]

9. Baker $\mathrm{H}$, Genter $\mathrm{M}$. The olfactory system and the nasal mucosa as portals of entry of viruses, drug, and other exogenous agents into the brain. In: Doty RL, editor. Handbook of Olfaction and Gustation. 2nd ed. New York: Marcel Dekker; 2003. p. 549-74.

10. Sorokowska A, Drechsler E, Karwowski M, Hummel T. Effects of olfactory training: a meta-analysis. Rhinology 2017; 55: 17-26. [CrossRef]

11. Tian J, Pinto JM, Cui $X$, et al. Sendai virus induces persistent olfactory dysfunction in a murine model of PVOD via effects on apoptosis, cell proliferation, and response to odorants. PLoS One 2016; 11: e0159033. [CrossRef]

12. Lee DY, Lee WH, Wee JH, Kim JW. Prognosis of postviral olfactory loss: follow-up study for longer than one year. Am J Rhinol Allergy 2014; 28: 419-22. [CrossRef]

13. Welge-Luessen A, Leopold DA, Miwa T. Smell and taste disorders - diagnostic and clinical work-up. In: Welge-Luessen A, Hummel $T$, editors. Management of smell and taste disorders - a practical guide for clinicians. Stuttgart: Thieme; 2013. p. 49-57. [CrossRef]

14. Deems DA, Doty RL, Settle RG, et al. Smell and taste disorders, a study of 750 patients from the University of Pennsylvania Smell and Taste Center. Arch Otolaryngol Head Neck Surg 1991; 117: 519-28. [CrossRef]

15. Rombaux $\mathrm{P}$, Collet $\mathrm{S}$, Martinage $\mathrm{S}$, et al. Olfactory testing in clinical practice. B-ENT 2009; 5 Suppl 13: 39-51.

16. Landis BN, Hummel $T$, Hugentobler $M$, Giger $R$, Lacroix JS. Ratings of overall olfactory function. Chem Senses 2003; 28: 691-4. [CrossRef]

17. Oleszkiewicz A, Hummel T. Whose nose does not know? Demographical characterization of people unaware of anosmia. Eur Arch Otorhinolaryngol. 2019; 276: 1849-52. [CrossRef]

18. Wilson DA, Best AR, Sullivan RM. Plasticity in the olfactory system: lessons for the neurobiology of memory. Neuroscientist 2004; 10 : 513-24. [CrossRef]

19. Mclntosh K. Coronavirus disease 2019 (COVID-19). UpToDate 2020. Available at: https://www.uptodate.com/contents/ coronavirus-disease-2019-covid-19-epidemiology-virology-clinical-features-diagnosis-and-prevention.

20. Wang D, Hu B, Hu C, et al. Clinical Characteristics of 138 hospitalized patients with 2019 Novel Coronavirus - infected pneumonia in Wuhan, China. JAMA 2020. [Epub ahead of print] [CrossRef]

21. Vaira LA, Salzano G, Deiana G, De Riu G. Anosmia and ageusia: common findings in COVID-19 patients. Laryngoscope 2020. [Epub ahead of print] [CrossRef]

22. Wujtewicz M, Dylczyk-Sommer A, Aszkielowicz A, Zdanowski $S$, Piwowarczyk S, Owczuk R. COVID-19 - what should anaethesiologists and intensivists know about it? Anaesthesiol Intensive Ther 2020; 52: 34-41. [CrossRef]

23. Kaye R, Chang CWD, Kazahaya K, Brereton J, Denneny JC. COVID-19 anosmia reporting tool: initial findings. Otolaryngol Head Neck Surg 2020. [Epub ahead of print]

24. Bojanowski $V$, Hummel T. Retronasal perception of odors. Physiol Behav 2012; 107: 484-7. [CrossRef]

25. Wang Z, Yang B, Li Q, Wen L, Zhang R. Clinical features of 69 cases with Coronavirus disease 2019 in Wuhan, China. Clin Infect Dis 2020. [CrossRef]

26. Huang $C$, Wang $Y, L i X$, et al. Clinical features of patients infected with 2019 novel coronavirus in Wuhan, China. Lancet 2020; 395: 497-506. [CrossRef] 
27. Zhonghua Liu Xing Bing Xue Za Zhi. The Epidemiological Characteristics of an Outbreak of 2019 Novel Coronavirus Diseases (COVID-19) in China. CHI J Epidemiol 2020; 17: 145-51. [Epub ahead of print] [CrossRef]

28. Hopkins C, Kumar N. Loss of sense of smell as marker for COVID-19 infection. 2020. Available at: https://www.entuk. org/sites/default/files/files/Loss $\% 20$ of\%20sense $\% 20$ of $\% 20$ smell\%20as\%20marker\%20of\%20COVID.pdf

29. Giacomelli A, Pezzati L, Conti F, et al. Self-reported olfactory and taste disorders in SARS-CoV-2 patients: a cross-sectional study. Clin Infect Dis 2020. [Epub ahead of print]

30. Netland J, Meyerholz DK, Moore S, Cassell M, Perlman S. Severe acute respiratory syndrome coronavirus infection causes neuronal death in the absence of encephalitis in mice transgenic for human ACE2. J Virol 2008; 82: 7264-75. [CrossRef]

31. Brann D, Tsukahara T, Weinreb C, et al. Non-neural expression of SARS-CoV-2 entry genes in the olfactory epithelium suggests mechanisms underlying anosmia in COVID-19 patients. 2020. Available at: https://www.biorxiv.org/content/10.1101/2020.03.2 5.009084v1 [CrossRef]

32. Eliezer M, Hautefort $\mathrm{C}$, Hamel AL, et al. Sudden and Complete Olfactory Loss Function as a Possible Symptom of COVID-19. JAMA Otolaryngol Head Neck Surg 2020. [Epub ahead of print] [CrossRef]

33. Lechien JR, Chiesa-Estomba CM, De Siati DR, et al. Olfactory and gustatory dysfunctions as a clinical presentation of mild-to-moderate forms of the coronavirus disease (COVID-19): a multicenter European study. Eur Arch Otorhinolaryngol 2020. [CrossRef]

34. Mao $L$, Jin $H$, Wang $M$, et al. Neurologic manifestations of hospitalized patients with Coronavirus disease 2019 in Wuhan, China. JAMA Neurol 2020. [Epub ahead of print] [CrossRef]

35. Yan CH, Faraji F, Prajapati DP, Boone CE, DeConde AS. Association of chemosensory dysfunction and COVID-19 in patients presenting with influenza-like symptoms. Int Forum Allergy Rhinol 2020. [Epub ahead of print] [CrossRef]

36. Klopfenstein T, Kadiane-Oussou NJ, Toko L, et al. Features of anosmia in COVID-19. Med Mal Infect 2020. [Epub ahead of print] [CrossRef]

37. Moein ST, Hashemian SMR, Mansourafshar B, Khorram-Tousi A, Tabarsi P, Doty RL. Smell dysfunction: a biomarker for COVID-19. Int Forum Allergy Rhinol 2020. [Epub ahead of print] [CrossRef]

38. Capelli M, Gatti P. Anosmia and COVID-19 in south Lombardy: description of the first cases series in Europe. B-ENT 2020; 16(1): 86-90.

39. Hopkins C, Kumar N. Loss of sense of smell as marker of COVID-19 infection. ENT UK 2020. Available at: https://www.entuk.org/sites/default/files/files/Loss\%20of\%20sense\%20of\%20 smell\%20as\%20marker\%20of\%20COVID.pdf

40. Information for rhinologists on COVID-19. Eur Rhinol Soc 2020. Available at: https://www.europeanrhinologicsociety.org/?page $\mathrm{id}=2143$

41. Information sur des formes cliniques atypiques de COVID-19 Paris: DGS-Urgent - Service pour les professionels de la santé Ministère des Affaires Sociales et de la Santé. 2020. Available at: Vroegop et al. COVID-19 and olfactory dysfunction B-ENT 2020
https://dgsurgent.sante.gouv.fr/dgsurgent/inter/detailsMessageBuilder.do?id=30700\&cmd=visualiserMessage [CrossRef]

42. Scheibe $M$, Bethge $C$, Witt $M$, Hummel T. Intranasal administration of drugs. Arch Otolaryngol Head Neck Surg 2008; 134: 6436. [CrossRef]

43. Shu CH, Lee PL, Shiao AS, Chen KT, Lan MY. Topical corticosteroids applied with a squirt system are more effective than a nasal spray for steroid-dependent olfactory impairment. Laryngoscope 2012; 122: 747-50. [CrossRef]

44. Damm M, Pikart LK, Reimann $\mathrm{H}$, et al. Olfactory training is helpful in postinfectious olfactory loss: a randomized, controlled, multicenter study. Laryngoscope 2014; 124: 826-31. [CrossRef]

45. Hummel T, Whitcroft KL, Rueter G, Haehner A. Intranasal vitamin A is beneficial in post-infectious olfactory loss. Eur Arch Otorhinolaryngol 2017; 274: 2819-25. [CrossRef]

46. Blakemore LJ, Trombley PQ. Zinc modulates olfactory bulb kainate receptors. Neuroscience 2020; 428: 252-68. [CrossRef]

47. Skrajnowska D, Bobrowska-Korczak B. Role of Zinc in immune system and anti-cancer defense mechanisms. Nutrients 2019; 11. [CrossRef]

48. Yan $\mathrm{CH}$, Rathor A, Krook K, et al. Effect of Omega-3 supplementation in patients with smell dysfunction following endoscopic sellar and parasellar tumor resection: a multicenter prospective randomized controlled trial. Neurosurgery 2020. [CrossRef]

49. Russell B, Moss C, Rigg A, Hopkins C, Papa S, Van Hemelrijck M Anosmia and ageusia are emerging as symptoms in patients with COVID-19: What does the current evidence say? Ecancermedicalscience 2020; 14: ed98. [CrossRef]

50. Russell CD, Millar JE, Baillie JK. Clinical evidence does not support corticosteroid treatment for 2019-nCoV lung injury. Lancet 2020; 395: 473-5. [CrossRef]

51. Lee N, Allen Chan KC, Hui DS, et al. Effects of early corticosteroid treatment on plasma SARS-associated Coronavirus RNA concentrations in adult patients. J Clin Virol 2004; 31: 304-9. [CrossRef]

52. Coronavirus disease 2019: World Health Organisation. Available at: https://www.who.int/emergencies/diseases/novel-coronavirus-2019/events-as-they-happen

53. Interim clinical guidance for management of patients with confirmed Coronavirus disease (COVID-19): centers for disease control and prevention. Available at: https://www.cdc.gov/coronavirus/2019-ncov/hcp/clinical-guidance-management-patients. html

54. Bousquet J, Akdis $C$, Jutel $M$, et al. Intranasal corticosteroids in allergic rhinitis in COVID-19 infected patients: an ARIA-EAACI statement. Allergy 2020. [Epub ahead of print] [CrossRef]

55. Steelant B, Seys SF, Van Gerven L, et al. Histamine and T helper cytokine-driven epithelial barrier dysfunction in allergic rhinitis. J Allergy Clin Immunol 2018; 141: 951-63 e8. [CrossRef]

56. Zhang JJ, Dong $X$, Cao YY, et al. Clinical characteristics of $140 \mathrm{pa}-$ tients infected with SARS-CoV-2 in Wuhan, China. Allergy 2020. [CrossRef]

57. Recommendations for inhaled asthma controller medications: Global Initiative for Asthma (GINA). Available at: https://ginasthma.org/recommendations-for-inhaled-asthma-controller-medications/ 